\title{
Frequent overexpression of cyclin D1 in sporadic pancreatic endocrine tumours
}

\author{
S S Guo, X Wu, A T Shimoide, J Wong, F Moatamed ${ }^{1}$ and \\ M P Sawicki
}

Department of Surgery, West Los Angeles VA Medical Center and the UCLA School of Medicine, Los Angeles, California 90095, USA

${ }^{1}$ Department of Pathology, West Los Angeles VA Medical Center and the UCLA School of Medicine, Los Angeles, California 90095, USA

(Requests for offprints should be addressed to M P Sawicki, Division of General Surgery, UCLA School of Medicine, Room 72-215,

CHS10833 Le Conte Avenue, Los Angeles, CA 90095-6904, USA; Email: msawicki@ucla.edu)

\begin{abstract}
Pancreatic endocrine tumours (PETs) occur sporadically or are inherited as part of the multiple endocrine neoplasia type-1 syndrome. Little is known about the molecular events leading to these tumours. Cyclin D1, a key regulator of the G1/S transition of the cell cycle, is overexpressed in a variety of human cancers as well as certain endocrine tumours. We hypothesized that similar to other endocrine tumours, cyclin D1 is overexpressed in human sporadic PETs. Cyclin D1 protein overexpression was found in 20 of 31 PETs (65\%) when compared with normal pancreatic tissue. Furthermore, Northern blot analysis suggests that cyclin D1 up-regulation occurs at the post-transcriptional level in some PETs. Because the key cell growth signalling pathways p42/p44/ERK (extracellular signal-regulated kinase), p38/MAPK (mitogenactivated protein kinase), and Akt/PKB (protein kinase B)
\end{abstract}

can regulate cyclin D1 protein expression in other cell types, pancreatic endocrine tumours were analysed with phospho-specific antibodies against the active forms of these proteins to elucidate a tissue-specific regulatory mechanism of cyclin D1 in PETs. We found frequent activation of the p38/MAPK and Akt pathways, but down-regulation of the ERK pathway, in cyclin D1 overexpressing PETs. This study demonstrates that cyclin D1 overexpression is associated with human sporadic PET tumorigenesis, and suggests that this up-regulation may occur at the post-transcriptional level. These findings will direct future studies of PETs towards cell cycle dysregulation and the identification of key growth factor pathways involved in the formation of these tumours.

Journal of Endocrinology (2003) 179, 73-79

\section{Introduction}

Pancreatic endocrine tumours (PETs) develop from neuroendocrine cells residing in and around the pancreas. These rare tumours occur either sporadically or are inherited as part of the multiple endocrine neoplasia type-1 syndrome (MEN-1). While PETs are well known for characteristic hormonal production related syndromes, such as Zollinger Ellison syndrome, they may also cause symptoms from local invasion as well as metastatic spread. There are few effective therapies for patients with PETs besides surgical management, and prognosis varies between excellent for those without metastasis to poor for those with metastasis. Knowledge of the molecular mechanisms leading to PET tumorigenesis would greatly facilitate the development of rational anti-tumour therapy, as well as provide diagnostic and prognostic markers.

Little is known regarding the molecular pathogenesis of PETs. The gene responsible for the MEN-1 syndrome, MEN1, was cloned in 1997 (Chandrasekharappa et al.
1997), and is mutated in 23\% of PETs (Guo \& Sawicki 2001). The tumour suppressor Smad4/DPC4 (Bartsch et al. 1999) is mutated in 50\% of nonfunctional tumours. Other tumour suppressors and oncogenes implicated in PET tumourigenesis include HER-2/neu (Evers et al. 1994, Terris et al. 1998), p16 ${ }^{\mathrm{INK} 4}$ (Muscarella et al. 1998), p27 (Guo et al. 2001), and p53 (Evers et al. 1994, Lin et al. 1997). Loss-of-heterozygosity studies have also suggested the involvement of tumour suppressor genes from chromosomes 1 (Ebrahimi et al. 1999, Guo et al. 2002b), 3p (Chung et al. 1997), 3q (Guo et al. 2002a), 11p, 16p (Chung et al. 1998), 17p (Beghelli et al. 1998) and 22q (Chung et al. 1998).

Cyclins are the regulatory subunits of the cyclin/Cdk (cyclin-dependent kinase) complexes. Cyclin D1 binds to $\mathrm{Cdk} 4 / 6$, and the resultant complex phosphorylates the retinoblastoma susceptibility gene product, $\mathrm{pRb}$. Sequential phosphorylation of $\mathrm{pRb}$ by cyclin D/Cdk4/6 and cyclin $\mathrm{E} / \mathrm{Cdk} 2$ inactivates $\mathrm{pRb}$ and allows cell-cycle progression through G1 (Fagan et al. 1994). Once this 
restriction-point is traversed, cells lose their mitogendependence and progress through the cell cycle until the restriction point of the next cell cycle is reached. Although there is variability amongst different cell systems, the synthesis and accumulation of the regulatory cyclins, in particular cyclin D1, is an important control of $\mathrm{pRb}$ phosphorylation (Grana \& Reddy 1995) (reviewed in Hatakeyama \& Weinberg 1995). Not surprisingly, many human cancers (e.g. breast, parathyroid, head and neck, gastric, oesophageal) have increased cyclin D1 expression (reviewed in Hunter \& Pines 1994), and cyclin D1 is a prognostic marker for many cancers (Bova et al. 1999, Keum et al. 1999, Samejima et al. 1999, Cuny et al. 2000, Itoi et al. 2000). Moreover, forced overexpression of cyclin D1 results in a shortened G1 phase, reduced cellular dependence on exogenous mitogens, and cell transformation (Bodrug et al. 1994, Wang et al. 1994). Finally, activation of Cdk 4 causes pancreatic $\beta$-islet proliferation while inactivation of Cdk4 results in $\beta$-islet hypoplasia and insulin-dependent diabetes (Rane et al. 1999).

Cyclin D1 expression is regulated by transcriptional and post-transcriptional mechanisms. At the transcriptional level, kinase pathways such as p38/MAPK (mitogenactivated protein kinase), c-Jun N-terminal kinase/SAPK (stress-activated protein kinase), and p42/p44/ERK (extracellular signal-regulated kinase) transmit exogenous growth signals to up-regulate cyclin D1 (Lavoie et al. 1996, Lee et al. 1999). Similarly, activation of the Akt/ PKB (protein kinase B) pathway can increase cyclin D1 expression through either transcriptional (Gille \& Downward 1999) or post-transcriptional mechanisms (Diehl et al. 1998, Muise-Helmericks et al. 1998). There is, however, tremendous tissue specificity in cyclin D1 regulation and conflicting data regarding the effects of these pathways on cyclin D1 expression between cell types. Such studies have not been performed on human pancreatic endocrine tissues.

We hypothesized that sporadic PETs have dysregulation of cyclin D1 similar to parathyroid adenomas and other endocrine tumours. Western blot analysis demonstrated frequent overexpression of cyclin D1 in sporadic PETs compared with normal pancreas tissues. Cyclin D1 overexpression was confirmed by immunohistochemistry (IHC) analysis on a subset of 5 sporadic PETs. Northern analysis suggests that cyclin D1 up-regulation in these tumours occurs at the post-transcriptional level. Using phospho-specific antibodies, we also show frequent activation of the p38/MAPK and Akt pathways, but down-regulation of the ERK pathway, in cyclin D1 overexpressing sporadic PETs. Our findings are strengthened by a recent report of frequent cyclin D1 overexpression in human sporadic PETs (Chung et al. 2000). Together, these two studies strongly suggest the importance of cyclin D1 up-regulation in the tumourigenesis of sporadic PETs.

\section{Materials and Methods}

\section{Tissue isolation}

Tumour samples were obtained from patients who have received extensive pre-operative evaluations at exploratory laparotomy. Tissues were snap-frozen in liquid nitrogen and stored at $-80{ }^{\circ} \mathrm{C}$.

\section{Institutional review and informed consent}

This study was performed under the auspices of the West LA, VA, Institutional review board, with appropriate institutional oversight. Informed consent was obtained from all patients from whom tissue samples were harvested.

\section{Protein isolation}

Tissues were homogenized using a Kontes pellet pestle (Fisher Scientific, Pittsburg, PA, USA) in CHAPS lysis buffer $(10 \mathrm{mM}$ Tris- $\mathrm{HCl}, \mathrm{pH} 7 \cdot 5,1 \mathrm{mM} \mathrm{MgCl}, 1 \mathrm{mM}$ EGTA, $0 \cdot 1 \mathrm{mM}$ benzamidine, $5 \mathrm{mM} \beta$-mercaptoethanol, $0.5 \%$ CHAPS, $10 \%$ glycerol). After $30 \mathrm{~min}$ incubation, centrifugation was performed and cellular debris discarded. The supernatant was stored at $-80{ }^{\circ} \mathrm{C}$ until use. Protein concentration was determined using the Bichinchonic method (Pierce Biotechnology, Rockford, IL, USA).

\section{Western blot analysis}

Protein samples were denatured in loading dye $(62.5 \mathrm{mM}$ Tris-HCl, 2\% SDS, 10\% glycerol, 0.1\% Bromophenol Blue, $50 \mathrm{mM}$ dithiothreitol) and boiled at $100{ }^{\circ} \mathrm{C}$. Equal amounts $(25 \mu \mathrm{g})$ of protein were loaded into each well and resolved in 10\% SDS-PAGE gel. The protein samples were transferred to Hybond-C Extra protein membrane (Amersham, Piscataway, NJ, USA), agitated in blocking solution $(20 \mathrm{mM}$ Tris, $140 \mathrm{mM} \mathrm{NaCl}, 5 \%$ dry milk, $0 \cdot 1 \%$ Tween 20 ), and probed with primary antibodies in primary antibody dilution buffer $(20 \mathrm{mM}$ Tris, $140 \mathrm{mM}$ $\mathrm{NaCl}, 5 \%$ bovine serum albumin, $0 \cdot 1 \%$ Tween 20 ). After hybridization with the appropriate secondary antibody (1:2000 dilution), blots were developed with ECL reagents according to the manufacturer's instructions (Amersham). Equal protein loading and transfer were reconfirmed with Ponseau S staining (Sigma, St Louis, MO, USA) of the blots. The expression level of cyclin D1 was normalized to that of $\beta$-tubulin, and the expression levels of phosphoAkt, phospho-p38, and phospho-ERK were normalized to those of total-Akt, total-p38, and total-ERK respectively.

\section{Antibodies}

Monoclonal mouse anti-cyclin D1 (Santa Cruz Biotechnology, Santa Cruz, CA, USA) was used at 1:500 dilutions. Monoclonal mouse anti- $\beta$-tubulin (Sigma Scientific) was used at 1:2000 dilutions. Rabbit polyclonal anti-total p38, anti-phospho-specific p38, anti-total Akt, 
anti-phospho-specific Akt, and anti-total ERK (New England Biolabs, Beverly, MA, USA) were used at 1:1000 dilutions. Mouse monoclonal anti-phospho-specific ERK (New England Biolabs) was used at 1:1000 dilutions. For IHC, monoclonal cyclin D1 (NeoMarkers, Fremont, CA, USA) was used at 1:50 dilutions.

\section{Immunohistochemistry}

Tissues (3 PETs with cyclin D1 overexpression - 14T, 78T, 111T; 2 PETs without cyclin D1 overexpression 226T, 250T) were taken from the frozen tissue bank, and fixed in formalin, ethanol, and xylene in an automated tissue processor (LX300 Tissue Processor, Fisher Scientific, Tustin, CA, USA). After tissues were embedded in paraffin, they were cut into $4 \mu \mathrm{m}$ thick slices and mounted onto slides. Target retrieval was performed with DAKO Target Retrieval Solution (DAKO Corporation, Carpenteria, CA, USA) at $95{ }^{\circ} \mathrm{C}$ for $20 \mathrm{~min}$ in a steamer, then cooled to room temperature. Slides were then placed into the DAKO Autostainer and stained using the DAKO LSAB2 System, Peroxidase (DAKO Corporation). Primary antibody was diluted in DAKO Antibody Diluent, and blocking was performed in DAKO Protein Block Serum-Free (DAKO Corporation). Signals were obtained using DAKO Liquid DAB Large Volume Substrate-Chromogen System (DAKO Corporation). Specificity of the antibody was confirmed by peptide blocking using the cyclin D1 peptide (NeoMarkers). Appropriate positive and negative controls were used.

\section{Northern blot analysis}

Tissues (2 PETs with cyclin D1 overexpression - 67T, 113T; 2 PETs without cyclin D1 overexpression - 7T, 43T) were homogenized (see above) and RNA was isolated according to the RNeasy Mini protocol (Qiagen, Santa Clarita, CA, USA). RNA was resolved in $1.2 \%$ FA Gel (1.2\% agarose, $20 \mathrm{mM}$ MOPS, $5 \mathrm{mM}$ sodium acetate, $1 \mathrm{mM}$ EDTA, adjusted to $\mathrm{pH} 7 \cdot 0)$, and transferred to a nitrocellulose membrane (Schleicher \& Schuell, Keene, NH, USA) by capillary transfer (Sambrook et al. 1989). Cyclin D1 cDNA was labelled by a random primed DNA labelling kit (Boehringer Mannheim, Mannheim, Germany) using $\left[\alpha-{ }^{32} \mathrm{P}\right] \mathrm{dCTP}$ (ICN Biomedical, Costa Mesa, CA, USA). Hybridization was performed with ExpressHyb Solution (Clontech, Palo Alto, CA, USA) according to the manufacturer's protocol.

\section{Results}

\section{Overexpression of cyclin D1 in sporadic PETs}

Cyclin D1 is a key regulatory protein for the G1-S transition of the cell cycle, and was first shown to be up-regulated in human endocrine tumours (Motokura et al. 1991). We hypothesized that similar to other
Table 1 Activation of growth signalling pathways in sporadic PETs with increased cyclin D1 expression. Western blots with tumour protein were probed with antibodies to cyclin D1 and phospho-specific as well as total forms of Akt/PKB, p38/MAPK, and $\mathrm{p} 42 / \mathrm{p} 44 /$ ERK. The Western data were normalized to the pancreas control band to eliminate the effect of different exposure times between the different Western blots, and quantified to a scale between $3-$ to $3+$ by two independent reviewers. $3+$ represents the strongest signal while 0 denotes a signal comparable to that of the control. Clinical phenotype and the presence of hepatic involvement in each tumour are also shown. There is up-regulation of the Akt and p38 pathways, but down-regulation of the ERK pathway in sporadic PETs. There is no particular correlation between growth pathway activation and clinical behaviour or tumour type

\begin{tabular}{|c|c|c|c|c|c|}
\hline \multirow[b]{2}{*}{ Case } & Phenotype & $\begin{array}{l}\text { Hepatic } \\
\text { involvement }\end{array}$ & Akt & p38 & ERK \\
\hline & & & & & \\
\hline $1 \mathrm{~T}$ & Gastrinoma & No & $1+$ & $3+$ & $2-$ \\
\hline $4 \mathrm{~T}$ & Gastrinoma & Yes & 0 & 0 & $3-$ \\
\hline $8 \mathrm{~T}$ & Gastrinoma & No & $1+$ & 0 & $3-$ \\
\hline $14 \mathrm{~T}$ & Gastrinoma & Yes & $1+$ & $2+$ & 0 \\
\hline 39T & VIPoma & No & 0 & 0 & $3-$ \\
\hline $67 \mathrm{~T}$ & Gastrinoma & No & $3+$ & 0 & $3-$ \\
\hline $78 \mathrm{~T}$ & Gastrinoma & No & $1+$ & 0 & $2-$ \\
\hline 83T & Non-functional & Yes & 0 & $2+$ & $3-$ \\
\hline $111 \mathrm{~T}$ & Non-functional & No & 0 & 0 & $3-$ \\
\hline $113 \mathrm{~T}$ & Gastrinoma & No & 0 & 0 & $3-$ \\
\hline 119T2 & Gastrinoma & No & $2+$ & $1+$ & $1+$ \\
\hline $124 \mathrm{~T}$ & Insulinoma & No & $1+$ & 0 & 0 \\
\hline 200TL3 & Gastrinoma & Yes & 0 & $1+$ & $3-$ \\
\hline 201T2C & Gastrinoma & No & $2+$ & $1+$ & $1-$ \\
\hline $202 \mathrm{~T}$ & Gastrinoma & No & $1+$ & $2+$ & $2-$ \\
\hline 206T1 & Gastrinoma & No & $2+$ & $2+$ & $1-$ \\
\hline $208 T$ & Gastrinoma & No & $1+$ & $1+$ & $3-$ \\
\hline $213 \mathrm{~T}$ & Gastrinoma & No & $1+$ & 0 & 0 \\
\hline $214 \mathrm{~T} 2$ & Gastrinoma & No & $2+$ & $1+$ & 0 \\
\hline $225 \mathrm{~T}$ & Gastrinoma & No & $1+$ & 0 & $2-$ \\
\hline
\end{tabular}

VIPoma, vasoactive intestinal peptide tumour.

endocrine tumours there is dysregulation of cyclin D1 in sporadic PETs. To assess the expression of cyclin D1 at the protein level, Western blot analysis was performed on 31 sporadic PETs. As shown in Table 1, 20 of 31 sporadic PETs (65\%) demonstrated overexpression of cyclin D1 by Western blot analysis compared with two normal pancreas controls. A representative Western blot is shown in Fig. 1. Protein concentration of tumour samples was performed by the Bichinchonic assay, and equal loading was demonstrated with Ponseau S staining (data not shown) as well as by stripping the blots and re-probing with $\beta$-tubulin antibody (Fig. 1).

To validate the Western blot data, IHC was performed in 5 sporadic PETs for which we had sufficient tumour material for analysis (Fig. 2 and data not shown). Of these 5 PETs analyzed by IHC, all three PETs found to have cyclin D1 overexpression by Western blot analysis (tumours 14T, 78T, and 111T) also demonstrated both nuclear and cytoplasmic staining of cyclin D1 by IHC. 


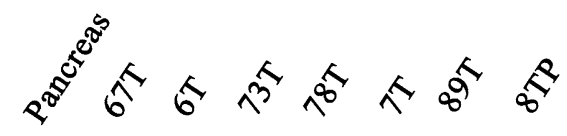

\section{Cyclin D1}

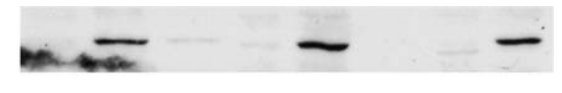

\section{$\beta$-tubulin}

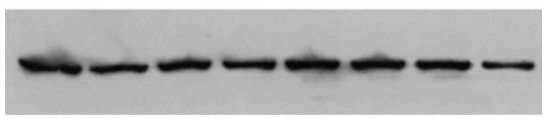

Figure 1 Cyclin D1 expression by Western blot in sporadic PETs. Tumours were snap-frozen at exploratory laparotomy, and stored at $-80{ }^{\circ} \mathrm{C}$. After protein isolation (see Materials and Methods), PETs were probed with cyclin D1 and representative Western blots are shown. Protein from two normal pancreases was used for control. Results from both pancreases were similar, and data from one is shown. The same blot was stripped and re-probed with $\beta$-tubulin to demonstrate similar protein loading among samples.

In contrast, two PETs without cyclin D1 overexpression by Western blot analysis (226T and 250T) showed undetectable cyclin D1 staining by IHC. Peptide blocking confirmed the specificity of our cyclin D1 antibody (Fig. 2a and $\mathrm{b})$. IHC demonstrated minimal contamination in the surrounding normal tissue in our samples.

Cyclin D1 overexpression occurs at the post-transcriptional level in sporadic PETs

One mechanism for cyclin D1 overexpression in many human tumours is through DNA amplification or rearrangement (e.g. breast cancer and parathyroid tumours), resulting in transcriptional up-regulation. However, previous studies did not reveal gross cytogenetic rearrangement or DNA amplification in the region of cyclin D1 in sporadic PETs (Sawicki et al. 1992, Terris et al. 1998, Speel et al. 1999). Cyclin D1 expression in sporadic PETs is therefore likely to occur through a transcriptional or a post-transcriptional mechanism. We investigated these possibilities by Northern blot analysis of 4 sporadic PETs (2 PETs with cyclin D1 overexpression - 67T, 214T2; 2 PETs without cyclin D1 overexpression - 7T, 43T). Figure 3 shows that although the level of cyclin D1 is dramatically different between these 4 sporadic PETs, their cyclin D1 mRNA expression is not significantly altered. This suggests that cyclin D1 overexpression may occur at the post-transcriptional level in sporadic PETs.

\section{Activation of MAP kinase pathways in pancreatic endocrine tumours}

Ras and its multiple effector pathways such as Akt, p38/MAPK, and p42/p44/ERK are known to have regulatory roles, through either transcriptional or posttranscriptional mechanisms, in the expression of cyclin D1
(Diehl et al. 1998, Muise-Helmericks et al. 1998, Lee et al. 1999). The active regulatory pathway is cell-type specific and context sensitive. No studies have been performed on human pancreatic endocrine tumour tissues.

We therefore investigated which Ras effector pathways might play an important role in cyclin D1 overexpression in sporadic PETs. Using phospho-specific antibodies and total-form antibodies against activated- and total-Akt, -p38/MAPK, and -p42/p44/ERK respectively, the activation status of these growth pathways in sporadic PETs was examined. Protein gel loading was equalized according to the total forms of these antibodies, and Western bands were quantified on a scale between $3-$ and $3+$ by two independent reviewers. As shown in Table 1, within the group of sporadic PETs that show cyclin D1 overexpression, there is activation of the Akt and/or the p38/MAPK growth pathways in $80 \%$ (16 of 20). In contrast, there is down-regulation of the ERK pathway in $75 \%$ (15 of 20) of the same group of samples. A representative Western blot is shown in Fig. 4.

\section{Cyclin D1 expression does not correlate with tumour aggressiveness or differentiation in sporadic PETs}

Because other studies have shown cyclin D1 to be a prognostic factor in human cancers (Bova et al. 1999, Keum et al. 1999, Samejima et al. 1999, Cuny et al. 2000, Itoi et al. 2000), cyclin D1 expression levels were analyzed for correlation with clinical tumour behaviour of these sporadic PETs. Tumours were categorized as benign or malignant based on the presence or absence of hepatic metastases. Of the six sporadic PETs that metastasized to the liver, four expressed increased levels of cyclin D1 $(67 \%)$ versus two that did not (Table 1 and data not shown). Conversely, of the 25 sporadic PETs without hepatic involvement, 16 expressed increased levels of cyclin D1 (64\%). Analysis according to tumour hormonal status (gastrinoma vs insulinoma vs nonfunctional tumours, etc.) also did not reveal any association with cyclin D1 overexpression. Thus there is no correlation between cyclin D1 overexpression and sporadic PET clinical aggressiveness or differentiation.

\section{Discussion}

In this study, 31 sporadic pancreatic endocrine tumours were analysed for the expression of cyclin D1 and 20 PETs (65\%) showed overexpression by Western blot analysis. These findings were validated by IHC in a subset of tumours. Although our sample size is limited, this is one of only two such studies in these rare and generally small tumours.

Previous studies showed no gross chromosomal rearrangement or DNA amplification in the region of cyclin D1 in sporadic PETs. This was confirmed by our 

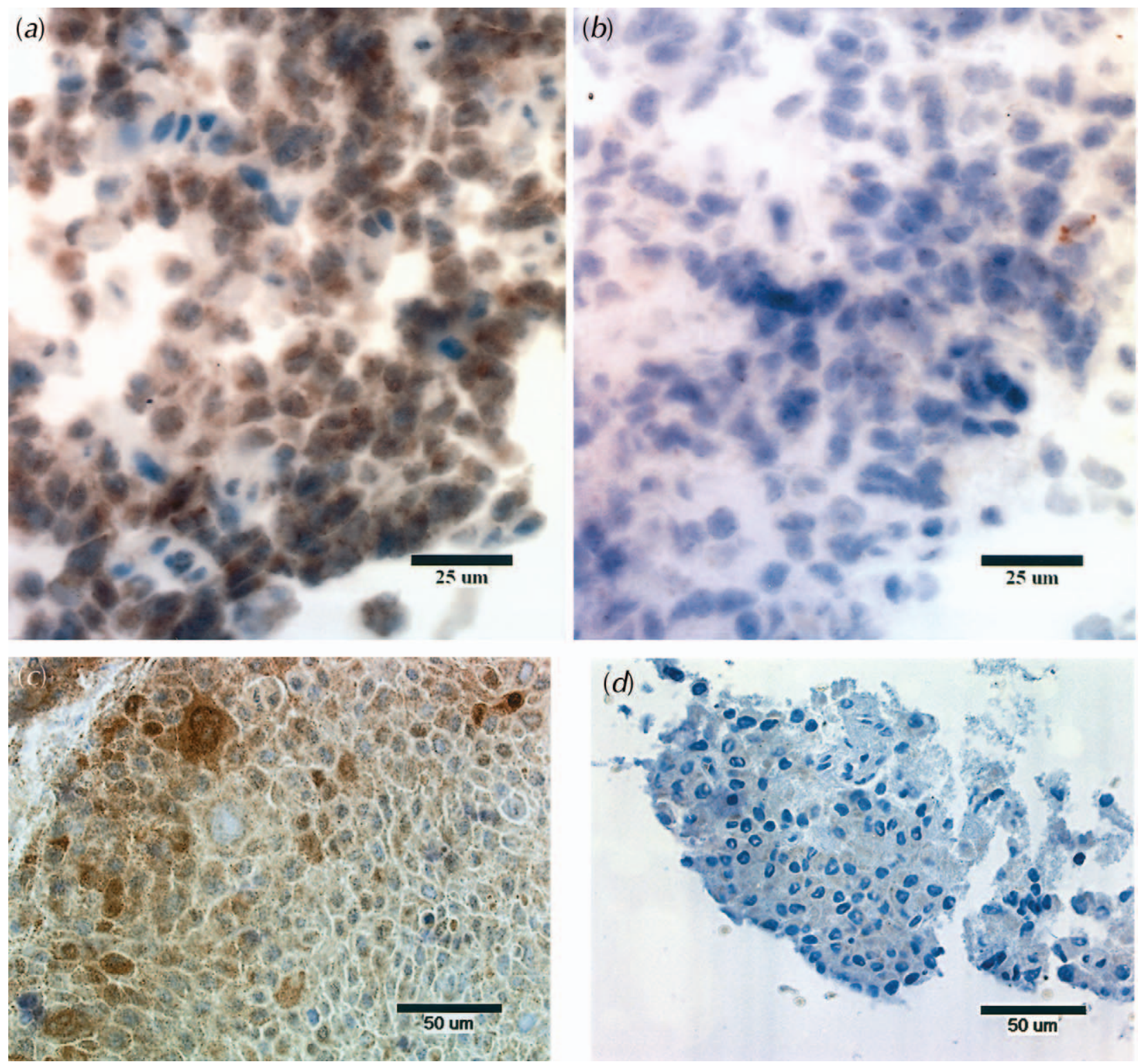

Figure 2 Cyclin D1 expression by IHC in sporadic PETs. Cyclin D1 overexpression was confirmed by IHC in 5 tumours (3 tumours with cyclin D1 overexpression - 14T, 78T, 111T; 2 PETs without cyclin D1 overexpression - 226T, 250T). Representative photomicrographs are shown. (a) Tumour (14T) found to have cyclin D1 overexpression by Western analysis has nuclear as well as cytoplasmic staining of cyclin D1 by IHC. (b) Specificity of the antibody used in immunohistochemistry is demonstrated with peptide blocking. Cyclin D1 staining in the same tumour is completely abolished with peptide blocking. (c) Large dysmorphic tumour cells can also be seen in another tumour with cyclin D1 overexpression. (d) A PET found to have no cyclin D1 overexpression (226T) by Western analysis also has no significant staining of cyclin D1.

Northern blot analysis that suggests in some sporadic PETs, post-transcriptional mechanisms are responsible for the up-regulation of cyclin D1 expression. Current studies in other cellular contexts demonstrated that the control of cyclin D1 expression by key growth regulatory pathways may be cell-type specific. We found activation of either the p38/MAPK or the Akt pathway in $80 \%$ (16 of 20 ) of sporadic PETs with cyclin D1 overexpression. In contrast, the ERK pathway is downregulated in $75 \%$ of these tumours (15 of 20). These observational studies on these rare human tumours may provide important clues for growth dysregulation in sporadic PETs.

In addition, no correlation between cyclin D1 overexpression and clinical behaviour or tumour phenotype was found. Studies of various human cancers suggest that 

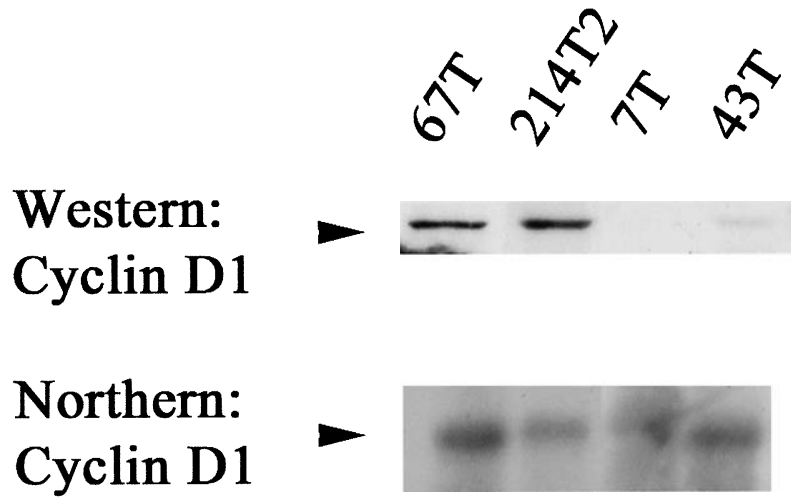

Figure 3 Cyclin D1 mRNA expression in sporadic PETs. Two cyclin D1 overexpressing tumours $(67 \mathrm{~T}, 214 \mathrm{~T} 2)$ and 2 tumours with normal cyclin D1 expression (7T, 43T) were analysed by Northern blot analysis. RNA was isolated from snap-frozen PETs and probed with radioisotope-labelled cyclin D1 cDNA. Northern blot bands and cyclin D1 Western blot bands of the same tumours are shown. The lack of increased signal on Northern blot analysis suggests that the increased cyclin D1 level occurred at the post-transcriptional level.

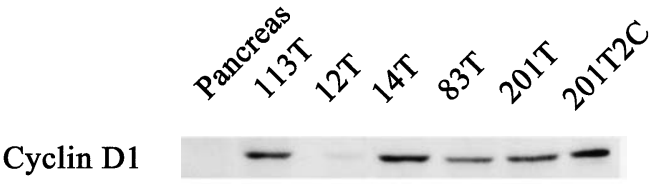

Phospho-AKT

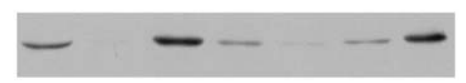

Total AKT

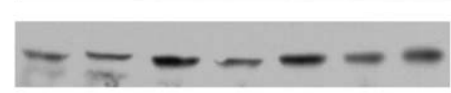

Phospho-p38

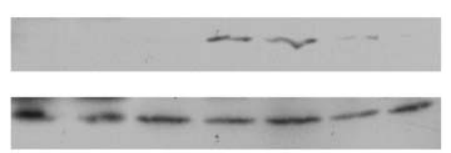

Total p38

\section{Phospho-ERK}

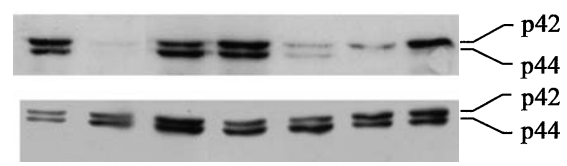

Total ERK

Figure 4 Activation of growth signalling pathways in sporadic PETs. Western blots were probed with phospho-specific and total forms of antibodies against Akt/PKB, p38/MAPK, and p42/p44/ERK. Protein loading was equalized according to the signal from the total forms of these antibodies. Representative blots are shown.

cyclin D1 overexpression may act either as a marker of tumour growth and aggressiveness, or as a marker of tumour differentiation. In sporadic PETs, however, neither aggressiveness (malignant vs benign behaviour) nor tumour differentiation (functional vs non-functional) correlate with cyclin D1 expression. It is possible that cyclin D1 dysregulation may occur before the tumour diverges into the different functional lineages or develops invasive behaviour. It may also be possible that cyclin D1 expression is a key indicator of generalized islet growth rather than tumour-specific changes. This is suggested by the findings of Rane et al. (1999) where activation of Cdk4 resulted in islet hyperplasia, but loss of Cdk4 led to insulin-deficient diabetes. Resolution of this issue will require functional studies in a suitable islet-specific model.

Recently, Chung et al. (2000) also found frequent overexpression of cyclin D1 in human PETs. While the frequency of overexpression was lower in their series $(43 \%$ vs $65 \%$ in this study), they also found that cyclin D1 overexpression did not correlate with the hormonal subtypes of the PETs. Although a trend was suggested between cyclin D1 overexpression and tumour aggressiveness, this was not statistically significant. Similarly, we found no correlation between cyclin D1 overexpression and hepatic metastasis. Finally, while their study suggested that cyclin D1 up-regulation may be at the transcriptional level, we failed to show differences in cyclin D1 mRNA levels between cyclin D1 overexpressing and nonoverexpressing tumours. This incongruity may be attributed to the small sample sizes in both of our studies (nine vs four tumours), and warrants further study.

In summary, we have shown that cyclin D1 is overexpressed in $65 \%$ of sporadic PETs. We have also shown that this cyclin D1 overexpression may be at the posttranscriptional level, and that the Akt, p38, and ERK pathways may play important roles in sporadic PETs. Further characterization of the G1/S transition dysregulation, as well as validation of the roles of these pathways by functional studies in suitable models, will yield a more complete understanding of the molecular mechanisms involved in the tumorigenesis of these rare tumours.

\section{Acknowledgements}

We express sincere gratitude to Drs Edward Passaro Jr and Gregory Brent for their intellectual discussion, support and guidance.

\section{Funding}

This research was funded by a VA MERIT award (to M P S) and a VA REAP grant (to S S G). There is no conflict of interest involved in this research.

\section{References}

Bartsch D, Hahn SA, Danichevski KD, Ramaswamy A, Bastian D, Galehdari H, Barth P, Schmiegel W, Simon B \& Rothmund M 1999 Mutations of the DPC4/Smad4 gene in neuroendocrine pancreatic tumors. Oncogene 18 2367-2371. 
Beghelli S, Pelosi G, Zamboni G, Falconi M, Iacono C, Bordi C \& Scarpa A 1998 Pancreatic endocrine tumours: evidence for a tumour suppressor pathogenesis and for a tumour suppressor gene on chromosome 17p. Journal of Pathology 186 41-50.

Bodrug SE, Warner BJ, Bath ML, Lindeman GJ, Harris AW \& Adams JM 1994 Cyclin D1 transgene impedes lymphocyte maturation and collaborates in lymphomagenesis with the myc gene. EMBO Journal 13 2124-2130.

Bova RJ, Quinn DI, Nankervis JS, Cole IE, Sheridan BF, Jensen MJ, Morgan GJ, Hughes CJ \& Sutherland RL 1999 Cyclin D1 and p16 INK4A expression predict reduced survival in carcinoma of the anterior tongue. Clinical Cancer Research 5 2810-2819.

Chandrasekharappa SC, Guru SC, Manickam P, Olufemi SE, Collins FS, Emmert-Buck MR, Debelenko LV, Zhuang Z, Lubensky IA, Liotta L et al. 1997 Positional cloning of the gene for multiple endocrine neoplasia-type 1. Science 276 404-407.

Chung D, Smith A, Louis D, Graeme-Cook F, Warshaw A \& Arnold A 1997 A novel pancreatic endocrine tumor suppressor gene locus on chromosome $3 \mathrm{p}$ with clinical prognostic implications. Journal of Clinical Investigation 100 404-410.

Chung D, Brown S, Graeme-Cook F, Tillotson L, Warshaw A, Jensen R \& Arnold A 1998 Localization of putative tumor suppressor loci by genome-wide allelotyping in human pancreatic endocrine tumors. Cancer Research 58 3706-3711.

Chung DC, Brown SB, Graeme-Cook F, Seto M, Warshaw AL, Jensen RT \& Arnold A 2000 Overexpression of cyclin D1 occurs frequently in human pancreatic endocrine tumors. Journal of Clinical Endocrinology and Metabolism 85 4373-4378.

Cuny M, Kramar A, Courjal F, Johannsdottir V, Iacopetta B, Fontaine H, Grenier J, Culine S \& Theillet C 2000 Relating genotype and phenotype in breast cancer: an analysis of the prognostic significance of amplification at eight different genes or loci and of p53 mutations. Cancer Research 60 1077-1083.

Diehl JA, Cheng M, Roussel MF \& Sherr CJ 1998 Glycogen synthase kinase- $3 \beta$ regulates cyclin D1 proteolysis and subcellular localization. Genes and Development 12 3499-3511.

Ebrahimi S, Wang EH, Wu A, Schreck RR, Passaro E Jr \& Sawicki MP 1999 Deletion of chromosome 1 predicts prognosis in pancreatic endocrine tumors. Cancer Research 59 311-315.

Evers BM, Rady PL, Sandoval K, Arany I, Tyring SK, Sanchez RL, Nealon WH, Townsend CM Jr \& Thompson JC 1994 Gastrinomas demonstrate amplification of the HER-2/neu proto-oncogene. Annals of Surgery 219 596-601.

Fagan R, Flint KJ \& Jones N 1994 Phosphorylation of E2F-1 modulates its interaction with the retinoblastoma gene product and the adenoviral E4 $19 \mathrm{kDa}$ protein. Cell 78 799-811.

Gille H \& Downward J 1999 Multiple ras effector pathways contribute to $\mathrm{G}(1)$ cell cycle progression. Journal of Biological Chemistry 274 22033-22040.

Grana X \& Reddy EP 1995 Cell cycle control in mammalian cells: role of cyclins, cyclin dependent kinases (CDKs), growth suppressor genes and cyclin-dependent kinase inhibitors (CKIs). Oncogene $\mathbf{1 1}$ 211-219.

Guo SS \& Sawicki MP 2001 Molecular and genetic mechanisms of tumorigenesis in multiple endocrine neoplasia type-1. Molecular Endocrinology 15 1653-1664.

Guo SS, Wu X, Shimoide AT, Wong J \& Sawicki MP 2001 Anomalous overexpression of p27(Kip1) in sporadic pancreatic endocrine tumors. Journal of Surgical Research 96 284-288.

Guo SS, Arora C, Shimoide AT \& Sawicki MP 2002a Frequent deletion of chromosome 3 in malignant sporadic pancreatic endocrine tumors. Molecular and Cellular Endocrinology 190 109-114.

Guo SS, Wu AY \& Sawicki MP $2002 b$ Deletion of chromosome 1, but not mutation of MEN-1, predicts prognosis in sporadic pancreatic endocrine tumors. World Journal of Surgery 26 843-847.

Hatakeyama M \& Weinberg RA 1995 The role of RB in cell cycle control. Progress in Cell Cycle Research 19-19.
Hunter T \& Pines J 1994 Cyclins and cancer. II: Cyclin D and CDK inhibitors come of age. Cell 79 573-582.

Itoi T, Shinohara Y, Takeda K, Nakamura K, Takei K, Sanada J, Horibe T, Saito T, Kasuya K \& Ebihara Y 2000 Nuclear cyclin D1 overexpression is a critical event associated with cell proliferation and invasive growth in gall bladder carcinogenesis. Journal of Gastroenterology 35 142-149.

Keum JS, Kong G, Yang SC, Shin DH, Park SS, Lee JH \& Lee JD 1999 Cyclin D1 overexpression is an indicator of poor prognosis in resectable non-small cell lung cancer. British Journal of Cancer $\mathbf{8 1}$ 127-132.

Lavoie JN, L'Allemain G, Brunet A, Muller R \& Pouysségur J 1996 Cyclin D1 expression is regulated positively by the $\mathrm{p} 42 / \mathrm{p} 44^{\mathrm{MAPK}}$ and negatively by the $\mathrm{p} 38 / \mathrm{HOG}^{\mathrm{MAPK}}$ pathway. Journal of Biological Chemistry 271 20608-20616.

Lee RJ, Alanese C, Stenger R, Watanabe G, Inghirami G, Haines III GK, Webster M, Muller WJ, Brugge JS, Davis RJ \& Pestell RG 1999 pp $60^{\mathrm{v}-\mathrm{src}}$ induction of cyclin D1 requires collaborative interactions between the extracellular signal-regulated kinase, p38, and Jun kinase pathways. Journal of Biological Chemistry 274 7341-7350.

Lin HJ, French SW, Reichenbach D, Wan YJ, Passaro E Jr \& Sawicki MP 1997 Novel p53 mutation in a malignant tumor secreting vasoactive intestinal peptide. Archives of Pathology and Laboratory Medicine 121 125-128.

Motokura T, Bloom T, Kim HG, Juppner H, Ruderman JV, Kronenberg HM \& Arnold A 1991 A novel cyclin encoded by a bcl1-linked candidate oncogene. Nature 350 512-515.

Muise-Helmericks RC, Grimes HL, Bellacosa A, Malstrom SE, Tsichlis PN \& Rosen N 1998 Cyclin D expression is controlled post-transcriptionally via a phosphatidylinositol 3-kinase/ Akt-dependent pathway. Journal of Biological Chemistry 273 29864-29872.

Muscarella P, Melvin WS, Fisher WE, Foor J, Ellison EC, Herman JG, Schirmer WJ, Hitchcock CL, DeYoung BR \& Weghorst CM 1998 Genetic alterations in gastrinomas and nonfunctioning pancreatic neuroendocrine tumors: an analysis of p16/MTS1 tumor suppressor gene inactivation. Cancer Research 58 237-240.

Rane SG, Dubus P, Mettus RV, Galbreath EJ, Boden G, Reddy EP \& Barbacid M 1999 Loss of Cdk4 expression causes insulin-deficient diabetes and Cdk4 activation results in beta-islet cell hyperplasia. Nature Genetics 22 44-52.

Sambrook J, Fritsch EF \& Manistis T 1989 Molecular Cloning, A Laboratory Manual, edn 2. New York: Cold Spring Harbor Laboratory Press.

Samejima R, Kitajima Y, Yunotani S \& Miyazaki K 1999 Cyclin D1 is a possible predictor of sensitivity to chemoradiotherapy for esophageal squamous cell carcinoma. Anticancer Research 19 5515-5521.

Sawicki MP, Wan YJ, Johnson CL, Berenson J, Gatti R \& Passaro E Jr 1992 Loss of heterozygosity on chromosome 11 in sporadic gastrinomas. Human Genetics 89 445-449.

Speel EJ, Richter J, Moch H, Egenter C, Saremaslani P, Rutimann K, Zhao J, Barghorn A, Roth J, Heitz PU \& Komminoth P 1999 Genetic differences in endocrine pancreatic tumor subtypes detected by comparative genomic hybridization. American Journal of Pathology 155 1787-1794.

Terris B, Meddeb M, Marchio A, Danglot G, Flejou JF, Belghiti J, Ruszniewski P \& Bernheim A 1998 Comparative genomic hybridization analysis of sporadic neuroendocrine tumors of the digestive system. Genes, Chromosomes and Cancer 22 50-56.

Wang TC, Cardiff RD, Zukerberg L, Lees E., Arnold A \& Schmidt EV 1994 Mammary hyperplasia and carcinoma in MMTV-cyclin D1 transgenic mice. Nature $369669-671$.

Received in final form 15 April 2003

Accepted 21 July 2003 